\title{
The Research on Modeling and Simulation of TFE Polymerization Process
}

\author{
Jing Gao Sun ${ }^{1,2}$ and Qin Cao ${ }^{1,2}$ \\ ${ }^{1}$ Key Laboratory of Advanced Control and Optimation for Chemical Processes of Ministry of Education, Shanghai 200237, China \\ ${ }^{2}$ School of Information Science and Engineering, East China University of Science and Technology, Shanghai 200237, China \\ Correspondence should be addressed to Jing Gao Sun; sunjinggao@126.com
}

Received 5 January 2014; Revised 10 March 2014; Accepted 13 March 2014; Published 16 April 2014

Academic Editor: Huaicheng Yan

Copyright (c) 2014 J. G. Sun and Q. Cao. This is an open access article distributed under the Creative Commons Attribution License, which permits unrestricted use, distribution, and reproduction in any medium, provided the original work is properly cited.

\begin{abstract}
PTFE (polytetrafluoroethylene) is the fluorinated straight-chain polymer, made by the polymerization of tetrafluoroethylene monomer; it is used widely because of its excellent performance and can be obtained by the polymerization of body, solutions, suspensions, and emulsions. But only the last two are the main ways. This research paper makes simulation based on Polymer Plus. It uses the emulsion polymerization method at background to carry out a semibatch reactor system. Upon the actual production conditions, simulation process under the steady state conditions is used to analyze the effects of the changes on operating conditions; the corresponding dynamic model is created to analyze the impact of the changes of conditions on the entire system. Moreover, the amount of APS which plays an important part in this reaction is discussed for getting the most suitable amount of initiator. Because of less research work on this job, it is so difficult to find the related data from the literature. Therefore, this research will have a great significance for the process of the tetrafluoroethylene emulsion polymerization in the future.
\end{abstract}

\section{Introduction}

Polytetrafluoroethylene is the most important species in the fluorine-containing polymer and it is applied in many industrial areas, such as aerospace and medical areas. In China, PTFE is mainly obtained from suspension polymerization, but the PTFE from dispersion polymerization [1-3] which contains superior performance and is used to apply in the preparation of expanded porous products and hydraulic hose products is so less. There is a great gap in the performance of the dispersion resin compared with the foreign countries.

With the rapid development of industry, the size of the PTFE's demand has become a national economic indicator, so dealing with the control system of the production process of PTFE not only can improve the quality of the product and reduce energy consumption during the reaction, but also can provide guidance and advise to the scene of the process operation. The PTFE emulsion obtained from TFE dispersion polymerization has been applied in many important areas; foreign researchers have done a lot of work in the synthesis of fluorinated polymer emulsion and made good results in the application of research [4-8]. Some patents about it are implied in the industrial area successfully. The countries in which science and technology are relatively developed have their own polymerization system. They have a very detailed presentation and research on the performance and application. However, they keep the process conditions and the recipe confidential; only a few patents involved are about this; most of the articles are the analysis of the synthesized product. Therefore, this paper about dispersion polymerization of TFE has a practical significance for the industrial craft process in domestic.

\section{Process Background of TFE Dispersion Polymerization}

The main object of this study is the polymerization process of tetrafluoroethylene which is commonly used in industry. It mainly uses the emulsion polymerization and semicontinuous feeding methods $[9,10]$, making ammonium persulfate as initiator and water as solvent. Because the initiator was decomposed under the acid condition, we add some glacial acetic acid to balance the liquid acid. Besides, we also should 
TABLE 1: The components involved in the reaction.

\begin{tabular}{lccc}
\hline Name & Type & Code name & Molecular formula \\
\hline Tetrafluoroethylene & Conventional & TFE & $\mathrm{C}_{2} \mathrm{~F}_{4}$ \\
Polytetrafluoroethylene & Polymer & PTFE & $\left(\mathrm{C}_{2} \mathrm{~F}_{4}\right)_{n}$ \\
Water & Conventional & $\mathrm{H}_{2} \mathrm{O}$ & $\mathrm{H}_{2} \mathrm{O}$ \\
Ammonium persulphate & Conventional & $\mathrm{APS}$ & $\left(\mathrm{NH}_{4}\right)_{2} \mathrm{~S}_{2} \mathrm{O}_{8}$ \\
TFE chain segments & Segment & $\mathrm{CF}_{2}-\mathrm{R}$ & $\mathrm{CF}_{2}-\mathrm{R}$ \\
Glacial acetic acid & Conventional & $\mathrm{CH}_{3} \mathrm{COOH}$ & $\mathrm{CH}_{3} \mathrm{COOH}$ \\
Dodecyl mercaptan & Conventional & DDM & $\mathrm{C}_{12} \mathrm{H}_{26} \mathrm{~S}$ \\
\hline
\end{tabular}

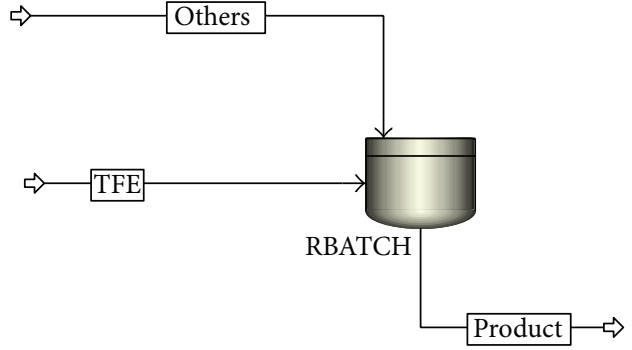

Figure 1: Process of the polymerization.

add stabilizer paraffin and chain transfer agent DDM; the main process can be summarized as follows: adding the deionized water and accessory ingredient (including initiators, stabilizers, modifiers, and chain transfer agent) which compounded well in advance (see Section 3.2); deflating and heating the reactor to make the temperature up to $70^{\circ} \mathrm{C}$ with stirring; after the detection of oxygen amount, adding TFE monomer and making the temperature and pressure to the specified value; and adding the monomer to keep the pressure at a certain value and, after some minutes, adding the perfluorooctanoic acid. After that we stop stirring and cooling the reactor. During the total process, the temperature should be kept between 80 and $105^{\circ} \mathrm{C}$; the pressure should be kept between 15 and $17 \mathrm{~atm}$. The static simulation process is shown in Figure 1.

\section{Steady-State Process Simulation and Analysis}

3.1. Polymerization Reaction Components. The chemical substances were divided into conventional, segment, oligomer, and polymer in polymer plus. They have the properties data like the boiling and melting point, the molecular structure, and molecular weight. Segment mainly includes repetitive unit, endpoint, and grafting site. The properties of the polymer are mainly dependent on the polymer segment type, quantity, and composition forms. The reaction components in this paper are shown in Table 1.

In this process, APS is $5 \mathrm{~g}, \mathrm{CH}_{3} \mathrm{COOH}$ is $250 \mathrm{~mL}, \mathrm{DDM}$ is $100 \mathrm{~g}$, and water is $400 \mathrm{~kg}$. And the feed temperature of TFE is $35^{\circ} \mathrm{C}$. Polymerization reactor is the main place of reaction, so its parameter setting is the most critical and important; in this paper, volume is set to $1.2 \mathrm{cum}$, the temperature is controlled between $80^{\circ} \mathrm{C}$ and $105^{\circ} \mathrm{C}$, and the pressure is controlled between $15 \mathrm{~atm}$ and $17 \mathrm{~atm}$. Since this reaction is a semicontinuous process, we make the reaction stop when PTFE yields reach to $150 \mathrm{~kg}$.

3.2. Polymerization Kinetics. The polymerization of tetrafluoroethylene is radical polymerization [11-13]; the reaction kinetics [14] mainly include four elementary reactions: chain initiator, chain growth [15], chain transfer, and chain termination [16]. The kinetic equation is expressed as follows:

(1) chain initiator: Aps $\rightarrow$ e.n.R $*+a \cdot A+b . B$; Tfe + $R * \rightarrow P_{1}[\mathrm{Tfe}]$

(2) chain growth: $P_{n}[\mathrm{Tfe}]+\mathrm{Tfe} \rightarrow P_{n+1}[\mathrm{Tfe}]$;

(3) chain transfer:

transfer to monomer: $P_{n}[\mathrm{Tfe}]+$ Tfe $\rightarrow D_{n}+P_{1}[\mathrm{Tfe}]$; transfer to the regulator: $P_{n}[\mathrm{Tfe}]+\mathrm{Ch}_{3} \operatorname{cooh} \rightarrow D_{n}+$ $R *$;

transfer to chain transfer agent: $P_{n}[\mathrm{Tfe}]+\mathrm{Ddm} \rightarrow$ $D_{n}+R *$;

(4) chain termination: $P_{n}[\mathrm{Tfe}]+P_{m}[\mathrm{Tfe}] \rightarrow D_{n+m}$;

The first step includes two parts: initiator decomposing to radical ion, combining with monomer to be monomer radical. The second step is the process of chain transfer and the third step is the process of transferring to monomer, chain transfer agent, and regulator. The end step is the process of coupling termination. $N$ is the number of the primary radical decomposition, $R *$ is the primary radicals, and $P_{1}$ represents that the polymerization degree of the living polymer is one. $P_{n}$ and $P_{m}$ are the polymeric chain of which unit length are $n$ and $m . D_{n}$ and $D_{n+m}$ are the die polymers of which length is $n$ and $m$, respectively.

Due to the diversity of PTFE process, polymerization kinetics data is also different; moreover, the confidentiality of technology makes it difficult to get the complete kinetic parameters. This paper combines the relative literature data and the correction in the actual simulation we have done, so it gets a better simulation effect. The polymerization of TFE is free radical polymerization, although Polymer Plus provides relevant radical polymerization model, but the kinetics parameters of different reactions are different and because of the diversity of PTFE process; kinetics parameters debugging is very difficult and time consuming. This paper combines literature data and the results of the simulation 
TABLE 2: Reaction rate and preexponential factor setting.

\begin{tabular}{lcccc}
\hline Type & Component 1 & Component 2 & Pre-Exp (1/sec) & Act-energy (J/kmol) \\
\hline INIT-DEC & APS & & $1.13 E+16$ & 137000000 \\
CHAIN-INI & C2F4 & & $3.62 E+13$ & 119710000 \\
PROPAGATION & C2F4 & C2F4 & 12490000 & 17413760 \\
CHAT-MON & C2F4 & C2F4 & 3320000 & 53020000 \\
CHAT-AGENT & C2F4 & CH3COOH & 1051 & 20000000 \\
CHAT-AGENT & C2F4 & DDM & 1051 & 20000000 \\
TERM-COMB & C2F4 & C2F4 & 1380000 & 13604500 \\
\hline
\end{tabular}

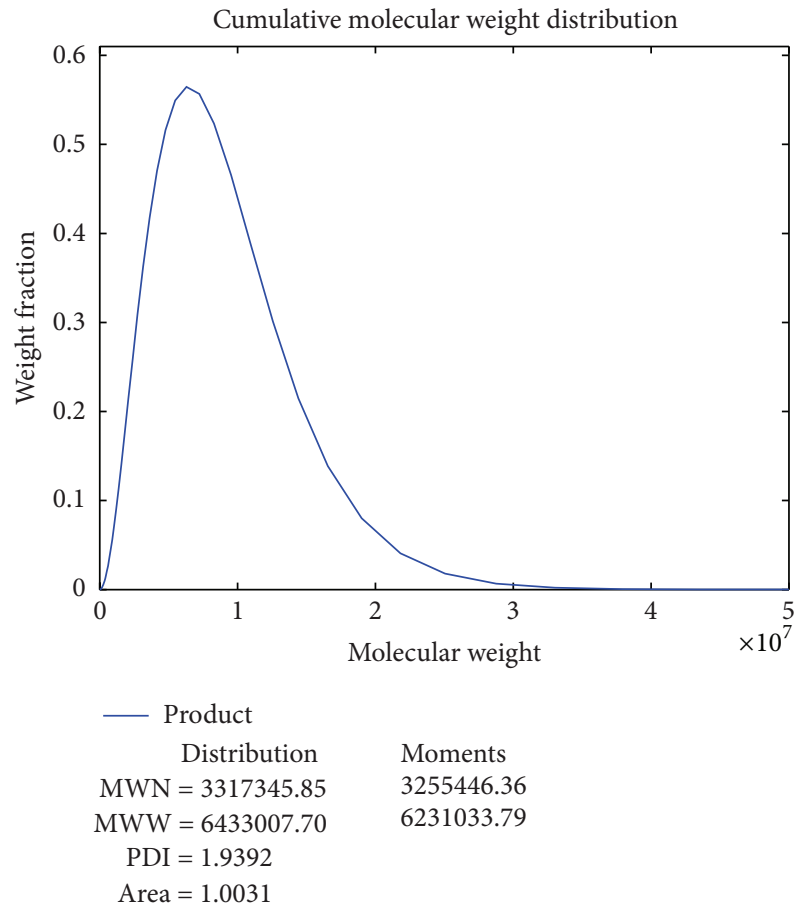

Figure 2: The MW distribution of polymer at $T=82^{\circ} \mathrm{C}$.

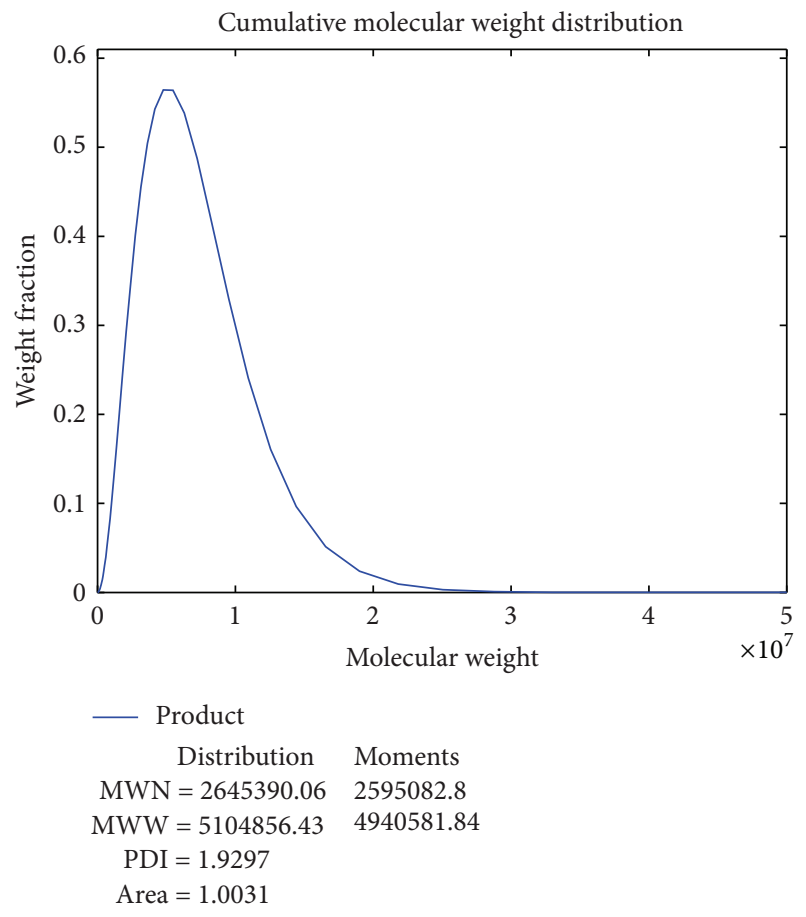

Figure 3: The MW distribution of polymer at $T=85^{\circ} \mathrm{C}$. based on the actual correction data; therefore, it gets a better simulation results. Table 2 is the setting of the kinetic parameters.

\subsection{The Analysis of the Steady State}

3.3.1. The Effect of Reactor Temperature on the Product. For the polymerization reaction, the reaction temperature directly affects the polymerization degree which reflects the quality of the product. Too low temperature will lead to slow response and the product with low intensity. On the contrary, the reaction rate will be rapid and the reaction is difficult to control. Low temperature will get low monomer conversion rate, because low molecular motion is not conducive to the proliferation of free radicals and the collision between monomers and radical. With the rises of the temperature, the chain growth rate constant and the number of the growth active centers both increase and the probability of spreading and collision between monomer and active radicals are elevated; meanwhile, the amount of PTFE increases leads to conversion rate of the monomer increasing. However, when the temperature reaches a certain stage, the curve of conversion rate will gradually tend to level because of the secondary reaction increasing, such as coupling termination and disproportionation termination. With the reaction proceeds continuing, the concentration of active centers is reduced, so the reaction rate is leveled off. The size of the molecular weight reaches unanimity basically as time increases. In order to investigate the impact of temperature on the molecular weight distribution of the polymer, the reactor temperature is set to $82^{\circ} \mathrm{C}, 85^{\circ} \mathrm{C}$, and $88^{\circ} \mathrm{C}$, respectively, observing the laws of the molecular weight distribution change with the different temperature; Figures 2, 3, and 4 show the change rules.

All the figures have shown the number-average molecular weight, weight-average molecular weight, and the dispersity of the polymer molecular weight in the relative temperature.

Figures 2 and 3 show that the number-average molecular weight of the product reduces to 2645390.8 from 3317345.81 


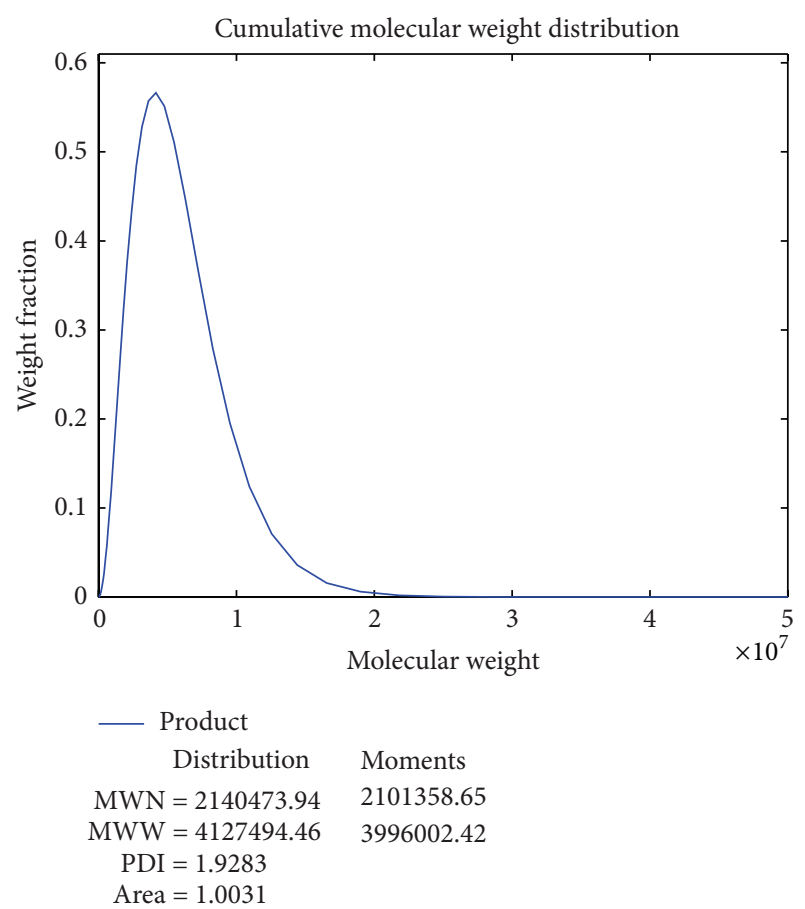

Figure 4: The MW distribution of polymer at $T=88^{\circ} \mathrm{C}$.

and weight-average molecular weight reduces to 5104856.48 from 6433007.62 when the temperature increases by 3 degree.

Figure 2, 3, and 4 show that the temperature changed the molecular weight and the overall curve move to the left when temperature increases; meanwhile, the curve is going to be narrow and steep. It is obvious that the increase of the temperature leads to the decrease of the molecular weight of polymer.

\subsubsection{The Effect of the Initiator on the Product. Figure 5 shows} the PTFE dispersion products molecular weight when APS is between $2 \mathrm{~g}$ and $8 \mathrm{~g}$. Initiator is one of the most important part of emulsion formulations; it cannot be too much or too little. The reaction speed will be too fast if its usage is too much, on the contrary, too little will make it difficult to trigger the reaction and is not good for the polymer performance.

Product conversion rate will increase gradually when initiator increases, and the rise of the primary free radicals will increase the frequency of chain initiator and then lead to the rise of the monomers conversion as well as reaction rate. Meanwhile, in the chain termination and chain transfer stage, the rise of the active end of the initiation phase accelerates the collision probability between primary radicals and active chain. Therefore, the length of the molecular chain becomes short; it means that PDI reduces gradually. However, too much initiator will be treated as the electrolyte and reduce the stability of the emulsion polymerization process.

3.3.3. The Effect of the Regulator Feed on the Product. Since the initiator agent decomposed under the acidic conditions, its half-life will be shortened when $\mathrm{PH}$ value reduces. Hence

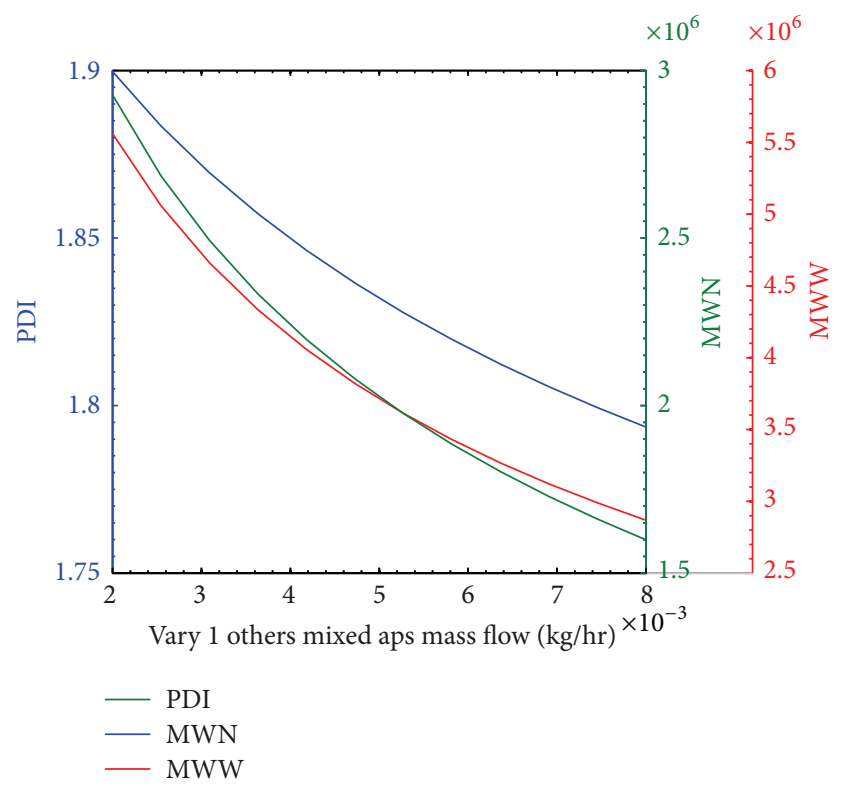

FIgURE 5: Effects of initiator flow on PDI.

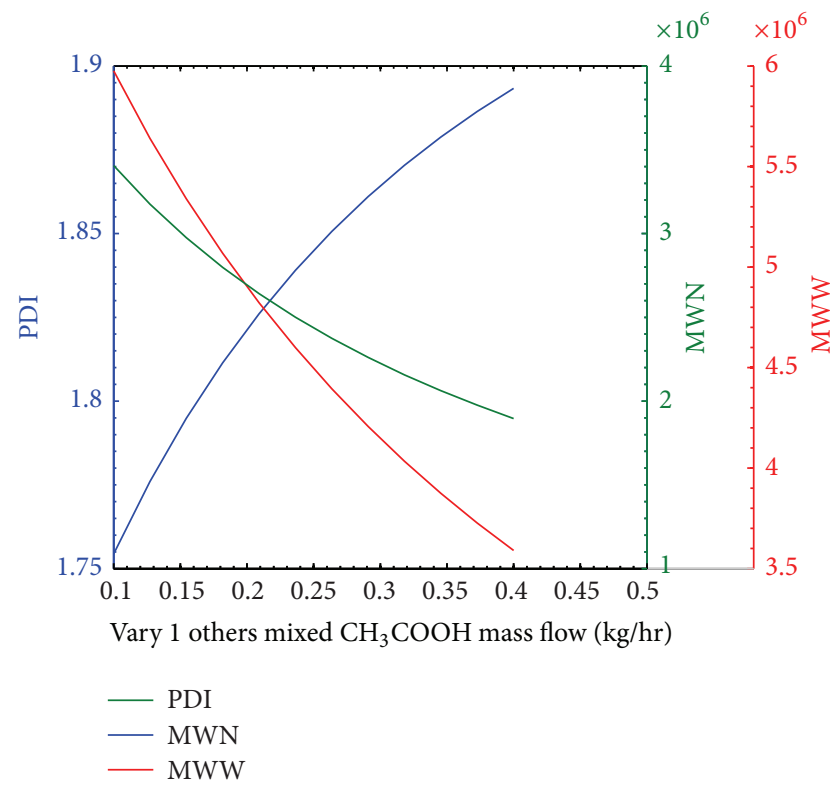

Figure 6: Effects of modifier flow on PDI.

we add the right amount of glacial acetic acid in the reactor to adjust the acidity of the liquid.

Figure 6 shows that PDI increases and the monomer conversion reduces as $\mathrm{CH}_{3} \mathrm{COOH}$ increases; this is because $\mathrm{CH}_{3} \mathrm{COOH}$ has a great effect on the polymerization reaction, especially in the liquid phase; it will be the chain transfer agent in the chain-transfer reaction. It is easy to react with growing macromolecular radicals and terminate the active chain, and the decrease of chain growth monomer will lead to the conversion rate reducing. Many active chains cann't get enough chain length and the value of PDI will increase, This is because the product with low molecular weight increases. 


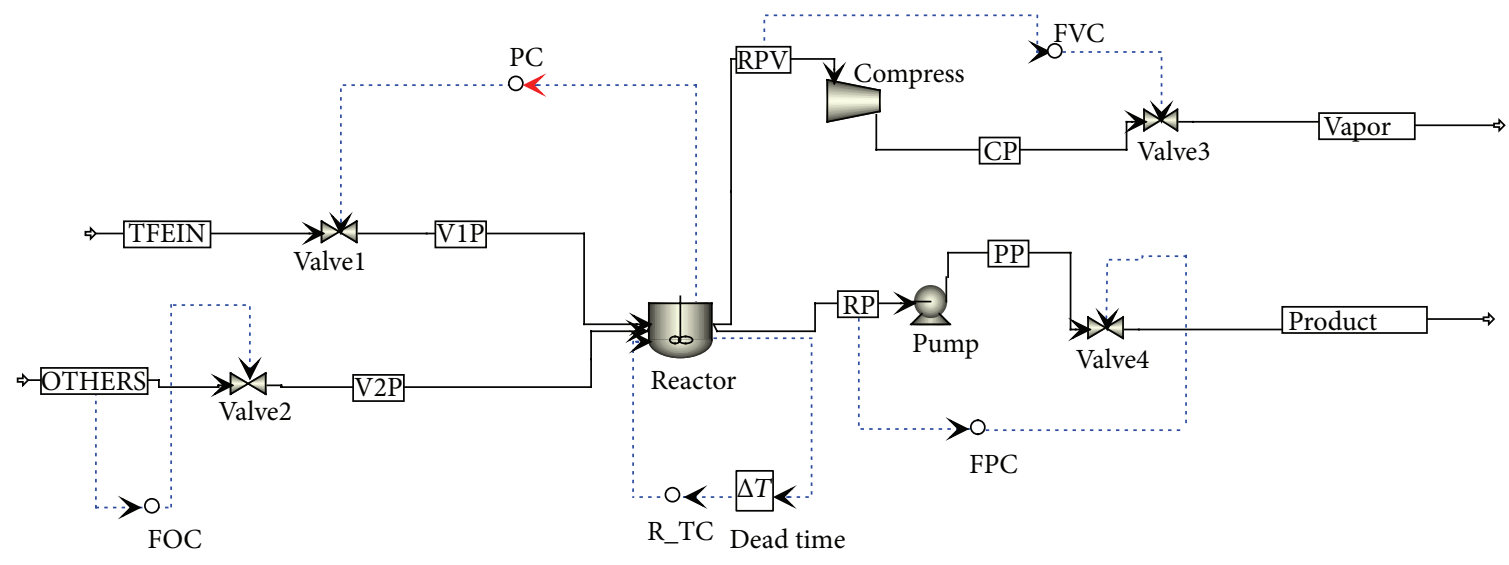

FIgURE 7: Process simulation of polymerization for TFE.

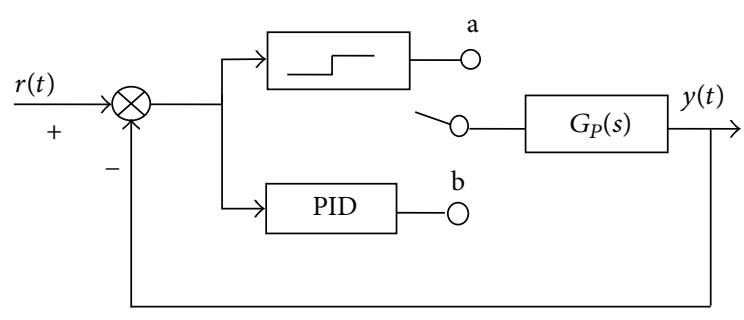

FIGURE 8: Relay feedback based parameter identification.

\section{Dynamic Modeling and Analysis}

4.1. The Establishment of Dynamic. Figure 7 is the dynamic process simulation; the pump and the compressor are mainly used to pump the air and discharge the liquid in the reactor. The valves are used to control the flow rate of each stream; OTHERS in Figure 7 represents water and accessory ingredient.

Pressure controller PC is used to control the opening degree of monomer valves through the reactor pressure and control the feeding amount indirectly. The temperature controller R_TC is mainly used to control the reactor temperature. The target value of reactor temperature is achieved by controlling the heat transfer.

4.2. The Setting of PID Controller Parameters. With the development of computer networks [17, 18], the control method is diverse. This paper introduces the autotuning PID controller based on relay feedback, shown in Figure 8, to control the process. There are test status and control status in the control system. In the former status, oscillation frequency and amplitude of the test system can be obtained from the relay link tested, and then the frequency domain information can be got in this case and it combines the control strategy to obtain the PID parameters. In the latter status, the system can be run through the PID parameters. In the process of the relay feedback control, the system can generate critical oscillation to obtain critical information as long as the controlled object has at least $-\pi$ phase lag. Setting the controller parameter based on Ziegler-Nichols tuning formula. The main steps can be summarized as follows: the system enters the steady state through manual control; making the soft switch to connect point a in Figure 8 to make the system generate constant amplitude oscillation to obtain amplitude and frequency, calculating the controller parameter based on the tuning method, adjusting parameters and entering the closed-loop control.

This method is widely applied because of its many advantages, the main advantages include that oscillations generated by the system are entirely the internal characteristics of nonlinear systems; the system will not only be disturbed and cannot be operated normally in the closed loop, but it also can overcome the impact of the PID parameter tuning from nonlinear system; it requires little prior knowledge.

The flow controllers (FVC, FOC, and FPC) in Figure 7 are used to control the valve opening to determine the material flow in and out. According to the conventional flow controller setting, these controllers are set as $P=0.5, I=0.3$, and they are added by $0.1 \mathrm{~min}$ filter time. Valves 3 and Valve 4 are used at the beginning of the reactor process simulation to evacuate the air and discharge the residuum. The setting of the pressure controller is not complex as temperature control. It needs PI control alone. From the experience value and relevant documentation records $[19,20]$, it can be set as $P=2$, $I=10$. After many repeated analysis of the simulation, the results prove that this parameter can get a good control effect.

The adjustment process of temperature is very complex. Temperature plays an important role on the product quality and safety of the entire polymerization process. It is difficult to achieve the desired effect with PI control only, so PID control should be used. In the setting of the parameter, the relay feedback based parameter identification method is used and a dead time between $30 \mathrm{~s}$ and $60 \mathrm{~s}$ is added. This dead time is also often discussed in network control [2123]. Considering that the dynamic temperature lag $[24,25]$ and the target value of the temperature setting cannot be reached immediately [26, 27], before the tuning of PID parameters, the hysteresis which equals to 1 minute needs to be added in the analog interface which includes the closedloop temperature controller. 


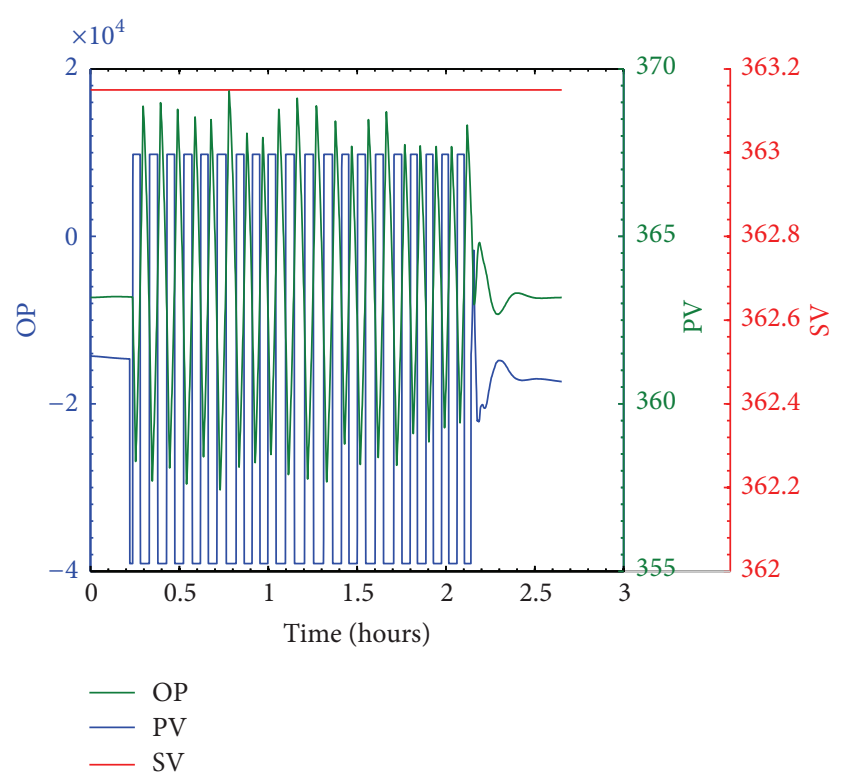

FIgURE 9: Relay-feedback test dynamic.

Figure 9 shows the process of autotuning based on relay feedback identification. Firstly, setting the target value of temperature to $363.15 \mathrm{~K}$ and using the relay feedback to acquire the amplitude and frequency of the system; secondly, ZieglerNichols rule was combined to it to get the PID parameter as $P=0.6187, I=2.82 \mathrm{~min}, D=0.705 \mathrm{~min}$. In order to get better result, the target value of temperature is set to $366.15 \mathrm{~K}$. Observing the result of this controller and modifying the parameter based on the former result to get the optimal parameter according to the overshoot and system response time. After many cycle tests, the best parameters can be acquired as $P=0.535137, I=3.27 \mathrm{~min}$, and $D=0.8175 \mathrm{~min}$.

4.3. The Analysis of the Dynamic Simulation Process. The overall process of TFE polymerization reaction can be briefly summarized in the following steps: cleaning the reactor $\rightarrow$ adding the deionized water and accessory ingredient $\rightarrow$ vacuating the reactor $\rightarrow$ adding the monomer $\rightarrow$ elevating temperature and pressure to a predetermined value $\rightarrow$ stirring $\rightarrow$ stoping the stirring when the product reaches the target value $\rightarrow$ cooling the reactor and recycling monomer.

4.3.1. Pressure and Monomer Feed Changes with Time. The first five hours are the reactor cleaning and solvent injecting. After that, the TFE is added to the reactor. Figure 10 shows that the pressure in the reactor increases gradually from vacuum state along with TFE feeding. Because the target of the pressure is set to $15 \mathrm{~atm}$, therefore, when the pressure exceeds this value, the opening degree of the valvel becomes smaller and feeding amount is also reduced. Besides, the feed input can be controlled by pressure controller very well in this picture. When the amount of the product meets its requirement, the feeding valve is closed. The gas in the reactor is consumed gradually; the pressure begins to drop.

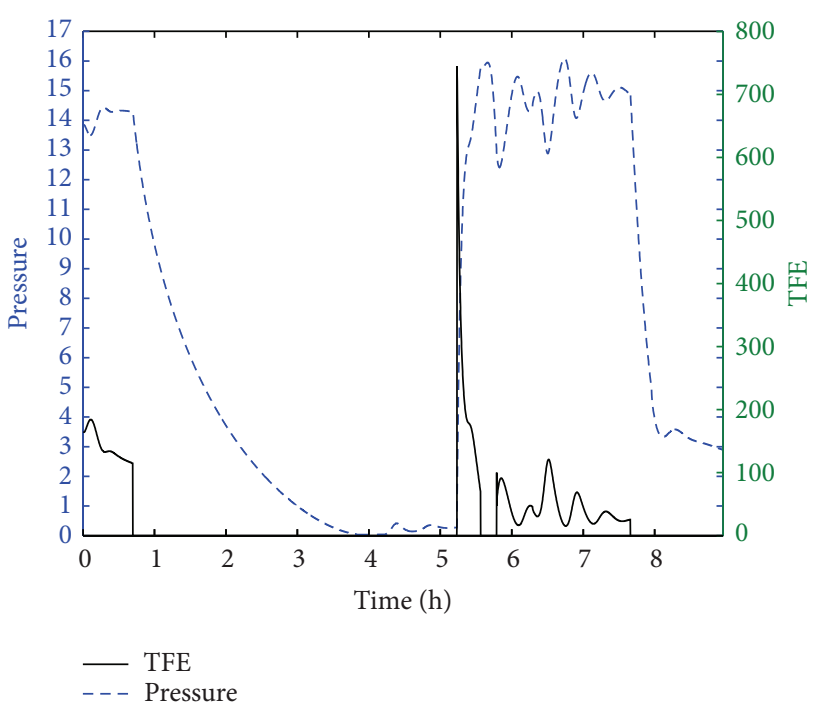

FIGURE 10: The change of the monomer feed and pressure.

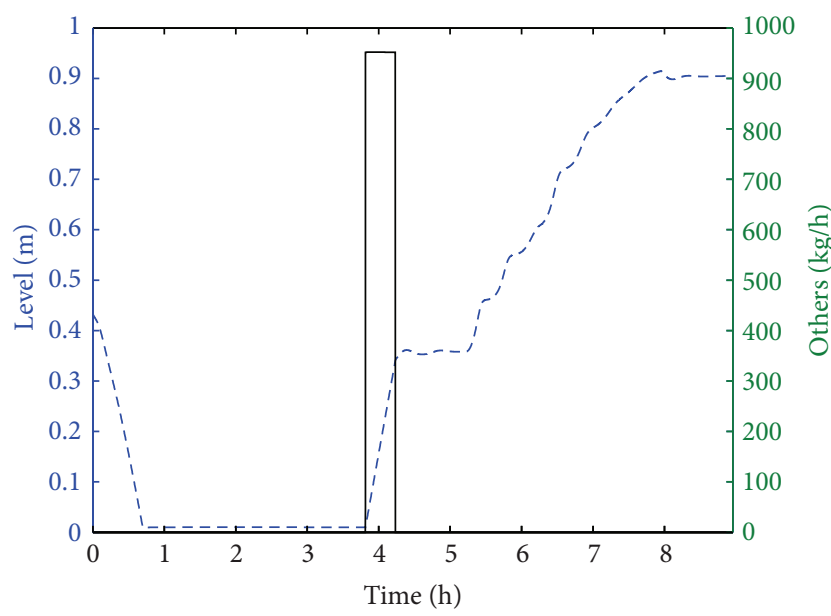

- Others
- - Level

FIGURE 11: The changes of level and other additives.

4.3.2. The Liquid Level and Accessory Ingredient Changes with Time. Reactor cleaning contains two steps: the liquid was discharged via a pump; the compressor evacuates the gas from the reactor. When the level reaches 0 and pressure is lower than vacuum state, injecting deionized water and accessory ingredient to the reactor with constant speed, the level rises to $0.4 \mathrm{~m}$ from the start level rapidly. When the water content reaches $400 \mathrm{~kg}$, valve 2 is closed and the reactor is heated to $70^{\circ} \mathrm{C}$. Figure 11 shows that the level rises when the monomer is injected to the reactor and PTFE is generated. When PTFE reaches the required yield, TFE feed valvel is closed. The pressure in the reactor decreases to some degree gradually and the reactor is cooling. The liquid level reaches a certain height and remains unchanged with the reaction stopping. 


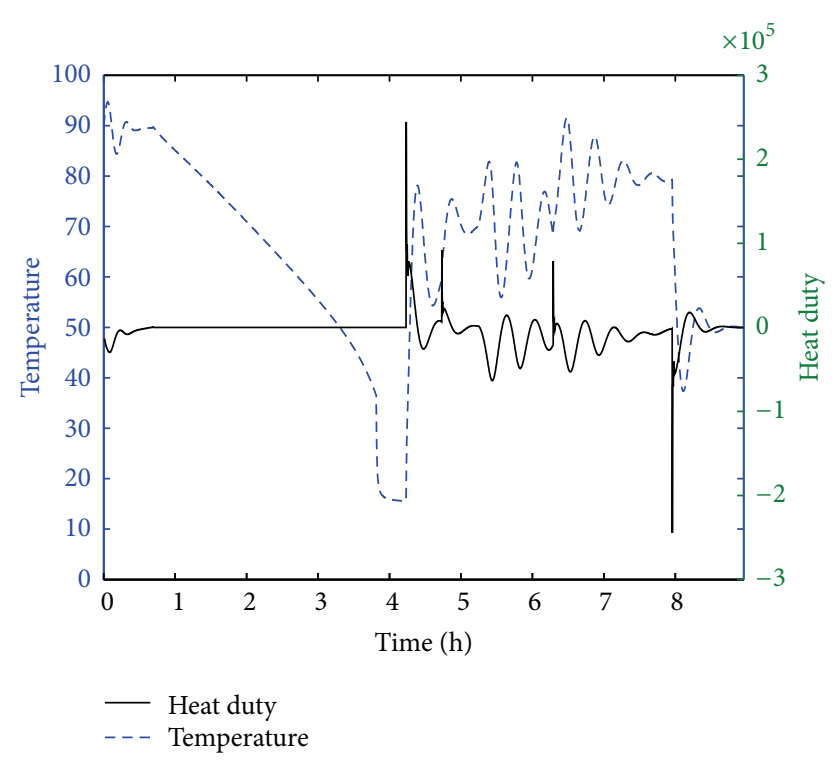

FIGURE 12: The change of the temperature and heat-duty.

4.3.3. Temperature and Heat Load Changes with Time. The dynamic reaction is directly converted from the static simulation and the temperature in the beginning of the dynamic process stayed in the static setting temperature. The temperature is not controlled by the controller during the process of clearing reactor. Discharging the substance from the reactor and evacuating the gas make the reactor temperature decline rapidly from the steady-state temperature at $95^{\circ} \mathrm{C}$ soon.

Figure 12 shows that the heat duty is in a constant state in the first 4 hours, after adding deionized water and accessory ingredient to the reactor, the reactor is heated to $75^{\circ} \mathrm{C}$. Then the monomer is injected and the reaction starts. This reaction is exothermic and the feed amount of the monomer is controlled by pressure, so the temperature changes constantly. The temperature is controlled by the transfer of the heat duty, so the size of the heat load will respond to the changes of the temperature. After the process is finished, the reactor is cooled when PTFE reaches the required yield.

4.3.4. The Amount of APS and PTFE Changes with Time. After injecting the solvents and accessory ingredient and heating the reactor, the initiator begins to decompose. The curve shows that PTFE is generated at five when temperature increases, meanwhile, APS decreases gradually and the decompose rate of APS in proportion to the temperature. Steady state is reached at the eighth hour; reactants and products are kept in a constant value. The changes of PTFE and APS are shown as in Figure 13.

\section{Analysis of the Initiator Dosage}

In general, APS begins to decompose when the temperature reaches $80^{\circ} \mathrm{C}$. The decomposition rate is in proportion to the temperature. The usage of initiator should be controlled within a certain range; too much initiator will lead to the reaction speed too fast and also the reaction will be difficult

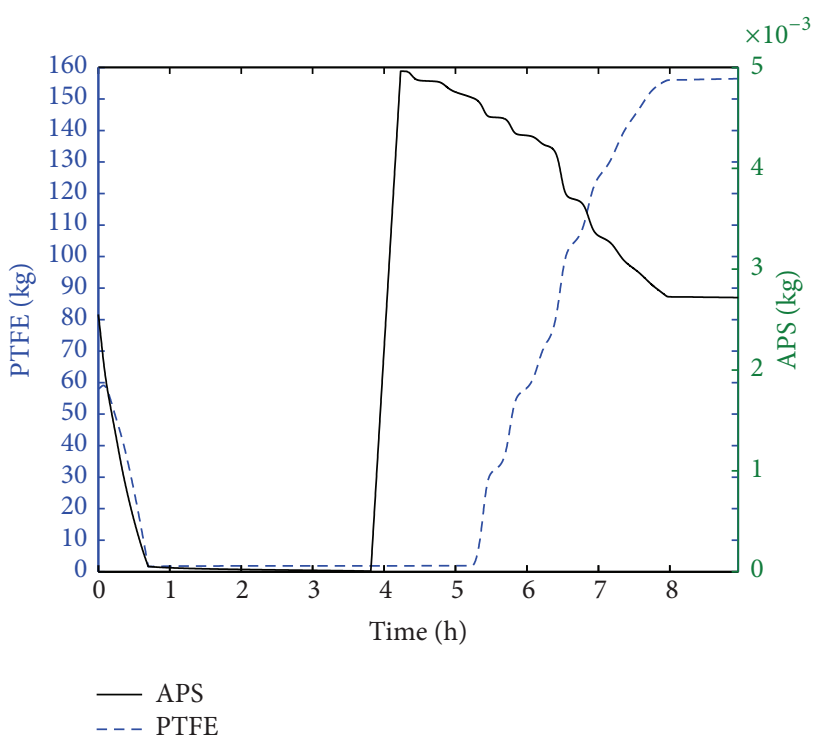

Figure 13: The change of PTFE and APS.

to be controlled well. Besides, polymerization degree of the product will be small and intensity will be low. Too little initiator will lead to the activity of initiator disappearing in the middle of the reaction; this will cause the reaction to not go on well. However, in the actual process, based on the premise of sufficient polymerization rate, the usage of the initiator should be minimum, because the residual initiator is not good for the product quality and the cost of initiator recycling is very high.

There are six dynamic simulations with different usage of APS which feed amount is from $2 \mathrm{~g}$ to $7 \mathrm{~g}$. For each simulation, the time required for the whole process is recorded. Meanwhile, APS's consumption and APS's residual amount should also be recorded in the end of each simulation. Then calculate the residual rate of APS. The final result is shown in Table 3.

Table 3 shows that the required reaction time increases first and then decreases, and the residual rate is converse; the reason is that the increase of the dose at the beginning results in the increase of residual. When the amount of initiator exceeds a certain amount, the reaction rate increases and temperature rises sharply; meanwhile, the decomposition rate of APS accelerates and leads to the decrease of the reaction half-life. According to the optimal choice of law, when the content of APS equals to $3 \mathrm{~g}$ and $2 \mathrm{~g}$, respectively, the total time required is close to or even more than 10 hours; it is a little long compared to other cases with different amounts of APS. When the amount of APS is equal to $7 \mathrm{~g}$, the quantity of the initiator is too much and this leads to the increase of the reaction rate; meanwhile, reaction heat cannot be removed in time to make temperature rise rapidly. Decomposition rate accelerates and retention rate is very low, but the total required time is 11 hours. This is because the initiator decomposes quickly and the reaction rate is very high; therefore, fewer initiators in later period make the reaction rate low. From the analysis above, we know that the amount of APS equaling to $2 \mathrm{~g}, 3 \mathrm{~g}$, and $7 \mathrm{~g}$ is not the optimal 
TABLE 3: The effect of different contents of APS.

\begin{tabular}{lcccc}
\hline Feed amount of APS $(\mathrm{g})$ & Consume amount of APS $(\mathrm{g})$ & Required reaction time $(\mathrm{h})$ & Residue amount of APS $(\mathrm{g})$ & Residual rate of APS \\
\hline 2 & 1.23 & 10.698 & 0.77 & 0.385 \\
3 & 1.672 & 9.792 & 1.328 & 0.443 \\
4 & 2.047 & 9.28 & 1.953 & 0.488 \\
5 & 2.49 & 8.956 & 2.51 & 0.507 \\
6 & 2.9 & 8.598 & 3.1 & 0.517 \\
7 & 6.77 & 11.644 & 0.23 & 0.033 \\
\hline
\end{tabular}

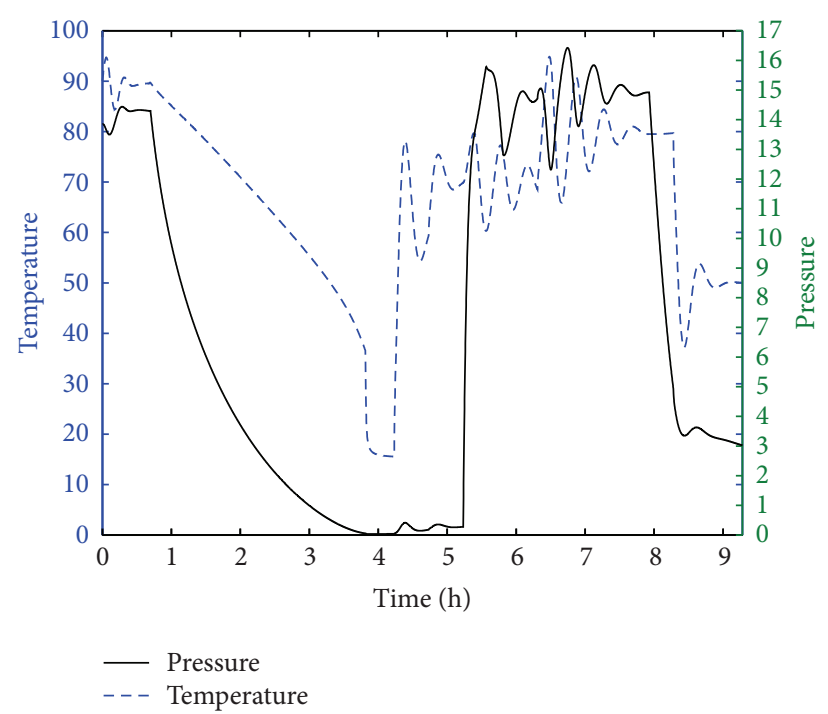

FIGURE 14: The effect on the reaction when APS $=4 \mathrm{~g}$.

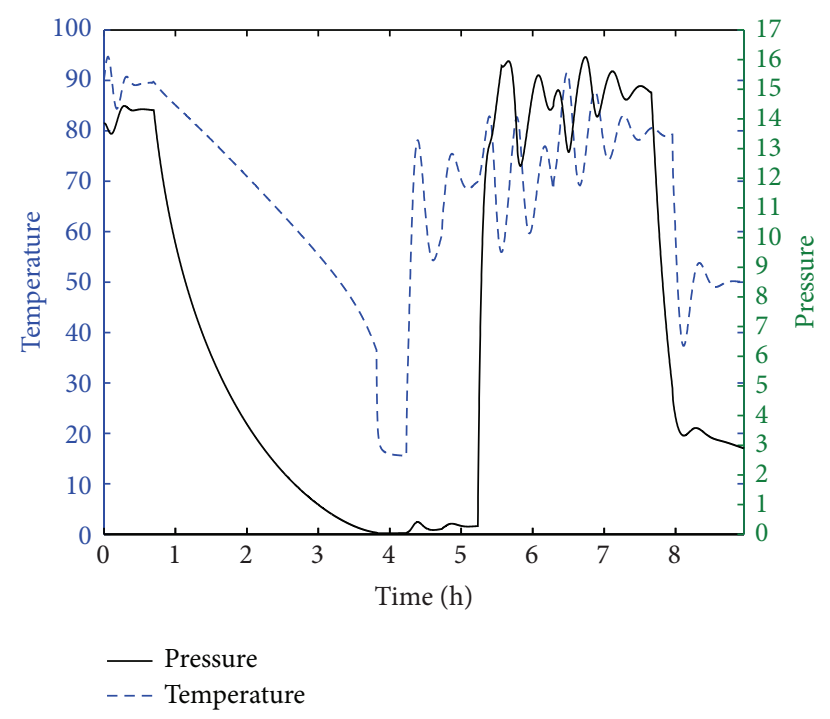

FIGURE 15: The effect on the reaction when APS $=5 \mathrm{~g}$.

content for this reaction. Figures $14,15,16$, and 17 show the the temperature and pressure of the reactor changes with time under the different amount of APS.

Figures 14, 15, 16, and 17 show that when the content of APS is $7 \mathrm{~g}$, temperature reaches $130^{\circ} \mathrm{C}$ and the pressure

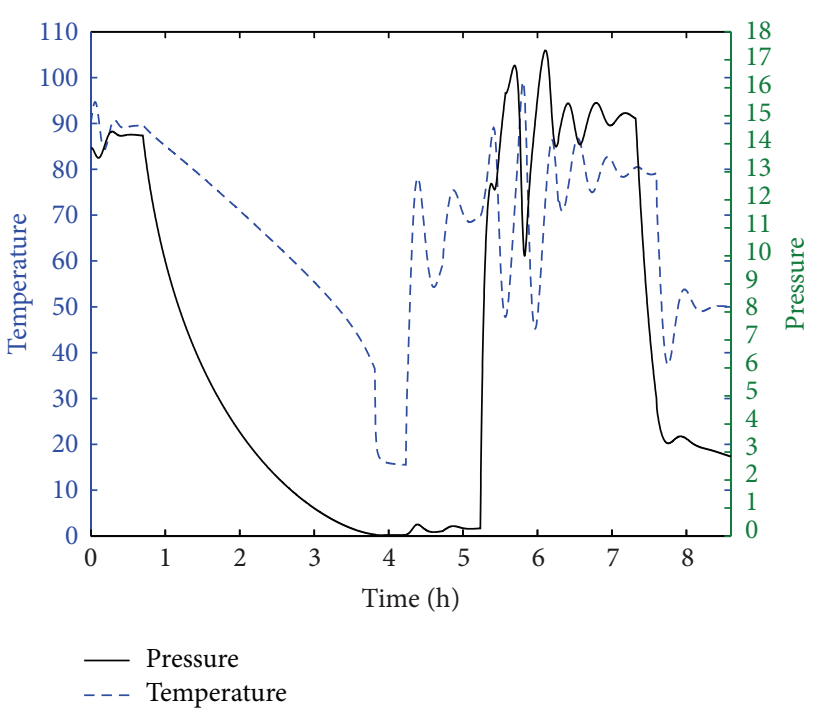

FIgURE 16: The effect on the reaction when APS $=6 \mathrm{~g}$.

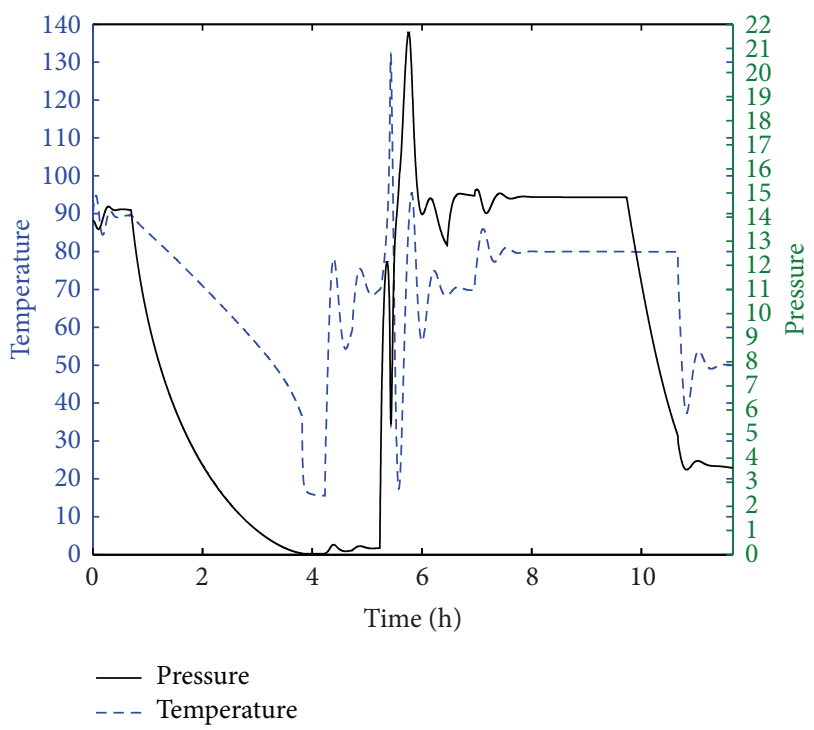

FIGURE 17: The effect on the reaction when APS $=7 \mathrm{~g}$.

reaches 22 atm. The high content of APS leads to the rapid reaction rate in this process, and it also causes the temperature and pressure is difficult to be controlled well. When the content of APS is $6 \mathrm{~g}$, the temperature rises suddenly 
and reaches $100^{\circ} \mathrm{C}$ after adding TFE; meanwhile, the pressure exceeds $17 \mathrm{~atm}$. When the content of APS is $4 \mathrm{~g}$ or $5 \mathrm{~g}$, the temperature and pressure are in the controllable range, but relatively speaking, when the content of APS is $5 \mathrm{~g}$, the temperature and pressure are controlled better. Table 1 also shows that productivity is higher and time consuming is less when APS is $5 \mathrm{~g}$.

\section{Conclusion}

This paper has established the steady state and dynamic simulation of TFE polymerization and analyzed the changes in reactants and products with increasing time, meanwhile combining the method of relay feedback identification and Ziegler-Nichols rule to set and adjust controller parameters to keep the variables in the reaction process controlled well. The dynamic simulation records the entire polymerization reaction from beginning to the end. And it also can record each stage of the reaction process well; from the curve, we know that the temperature includes heating, balance, and cooling stages and the monomer feeding amount that is controlled by pressure controller is also ups and downs due to the pressure inside the reactor. PTFE and initiators increase and decrease gradually along with the reaction process. For APS part, we examine the influence on the reaction mainly through the total reaction time, the residual amount and the ease of control. The results show that when the content of APS is equal to $5 \mathrm{~g}$, the reaction can not only be controlled well, but also guarantees a good rate of polymerization.

\section{Conflict of Interests}

The authors declare that there is no conflict of interests regarding the publication of this paper.

\section{References}

[1] C. U. Kim, J. M. Lee, and S. K. Ihm, "Emulsion polymerization of tetrafluoroethylene: effects of reaction conditions on the polymerization rate and polymer molecular weight," Journal of Applied Polymer Science, vol. 73, no. 5, pp. 777-793, 1999.

[2] C. U. Kim, J. M. Lee, and S. K. Ihm, "Emulsion polymerization of tetrafluoroethylene: effects of reaction conditions on particle formation," Journal of Fluorine Chemistry, vol. 96, no. 1, pp. 1121, 1999.

[3] J. Zeaiter, J. Romagnoli, and V. G. Gomes, "Reactor operating strategy and secondary nucleation in emulsion polymerization," International Journal of Chemical Reactor Engineering, vol. 2, no. 1, pp. 1-15, 2004.

[4] C. U. Kim, J. M. Lee, and S. K. Ihm, "Emulsion polymerization of tetrafluoroethylene: effect of reaction conditions on the polymerization rate and polymer molecular weight," Journal of Applied Polymer Science, vol. 73, no. 5, pp. 789-792, 1999.

[5] Y. Tabata, W. Ito, and K. Oshima, "Radiation-induced polymerization of tetrafluoroethylene," Journal of Macromolecular Science A: Chemistry, vol. 4, no. 4, pp. 789-799, 1970.

[6] L. B. Zorina and V. P. Mel'nikov, "Polymerization of tetrafluoroethylene initiated by fluorinated petroleum coke," Polymer Science A, vol. 50, no. 9, pp. 942-947, 2008.
[7] J. Ramos and J. Forcada, "Modeling the emulsion polymerization of amino-functionalized latex particles," Polymer, vol. 47, no. 4, pp. 1405-1413, 2006.

[8] Y. Tabata, W. Ito, K. Oshima, and J. Takaci, "Radiation-induced polymerization of tetrafluoroethylene in solution," Journal of Macromolecular Science, vol. 4, no. 4, pp. 815-824, 1970.

[9] X. Zhen and M. P. Duduković, "Modeling and simulation of semi-batch photo reactive distillation," Chemical Engineering Science, vol. 54, no. 10, pp. 1397-1403, 1999.

[10] F. Dong, Study on synthesis of ethylene glycol monoethers in semibatch reactor [M.S. thesis], Ocean University of China, 2008.

[11] N. Hamashima, "Monte Carlo simulation of size exclusion chromatography for branched polymers formed through freeradical polymerization with chain transfer to polymer," Macromol Theory Simulation, vol. 9, no. 8, pp. 453-462, 2000.

[12] S. Thomas, A. Hamielec, and J. Soares, "Free radical polymerization-an elegant method of solving the population balance equations with chain transfer to polymer," Polymer Reaction Engineering, vol. 5, no. 4, pp. 183-203, 1997.

[13] G. Moad and D. H. Solomon, The Chemistry of Radical Polymerization, Elsevier, 2006.

[14] Y. J. Huang and L. J. Lee, "Kinetics of free radical polymerizations in reactive polymer processing," American Institute of Chemical Engineers Journal, vol. 31, no. 10, pp. 1585-1593, 1985.

[15] O. F. Olaj, P. Vana, M. Zoder, A. Kornherr, and G. Zifferer, "Is the rate constant of chain propagation $\mathrm{kp}$ in radical polymerization really chain-length independent?" Macromolecular Rapid Communications, vol. 21, no. 13, pp. 913-920, 2000.

[16] I. N. Meshkova, V. I. Tsvetkova, and N. M. Chirkov, "Chain termination reactions in the polymerization of ethylene over $\mathrm{TiCl}_{4}-\mathrm{AIR}_{2} \mathrm{Cl}$," Bulletin of the Academy of Sciences of the USSR, Division of Chemical Science, vol. 12, no. 5, pp. 732-737, 1963.

[17] L. X. Zhang, H. J. Gao, and O. Kaynak, "Network-induced constraints in networked control systems-a survey," IEEE Transactions on Industrial Informatics, vol. 9, no. 1, pp. 403-416, 2013.

[18] H. C. Yan, H. B. Shi, H. Zhang, and F. W. Yang, "Quantized $H_{\infty}$ control for networked systems with communication constraints," Asian Journal of Control, vol. 15, no. 5, pp. 1468-1476, 2013.

[19] W. L. Luyben, Chemical Reactor Design and Control, WileyBlackwell, 2007.

[20] W. L. Luyben, Distillation Design and Control Using Aspen Simulation, American Institute of Chemical Engineers, 2006.

[21] H. Zhang, H. C. Yan, F. W. Yang, and Q. J. Chen, "Quantized control design for impulsive fuzzy networked systems," IEEE Transactions on Fuzzy Systems, vol. 19, no. 6, pp. 1153-1162, 2011.

[22] H. Zhang, H. C. Yan, F. W. Yang, and Q. J. Chen, "Distributed average filtering for sensor networks with sensor saturation," IET Control Theory \& Applications, vol. 7, no. 6, pp. 887-893, 2013.

[23] H. C. Yan, Z. Z. Su, H. Zhang, and F. W. Yang, "Observerbased $H_{\infty}$ control for discrete-time stochastic systems with quantisation and random communication delays," IET Control Theory \& Applications, vol. 7, no. 3, pp. 372-379, 2013.

[24] H. J. Gao, T. W. Chen, and J. Lam, "A new delay system approach to network-based control," Automatica, vol. 44, no. 1, pp. 39-52, 2008.

[25] H. Zhang, Z.-H. Guan, and G. Feng, "Reliable dissipative control for stochastic impulsive systems," Automatica, vol. 44, no. 4, pp. 1004-1010, 2008. 
[26] H. Zhang, Q. J. Chen, H. C. Yan, and J. H. Liu, "Robust $H_{\infty}$ filtering for switched stochastic system with missing measurements," IEEE Transactions on Signal Processing, vol. 57, no. 9, pp. 3466-3474, 2009.

[27] H. Zhang, H. C. Yan, T. Liu, and Q. J. Chen, "Fuzzy controller design for nonlinear impulsive fuzzy systems with time delay," IEEE Transactions on Fuzzy Systems, vol. 19, no. 5, pp. 844-856, 2011. 


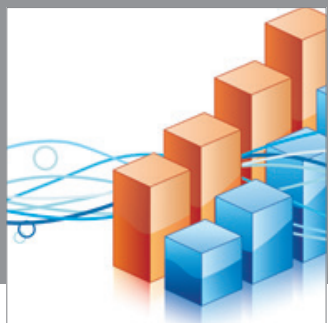

Advances in

Operations Research

mansans

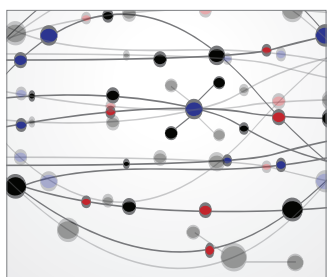

The Scientific World Journal
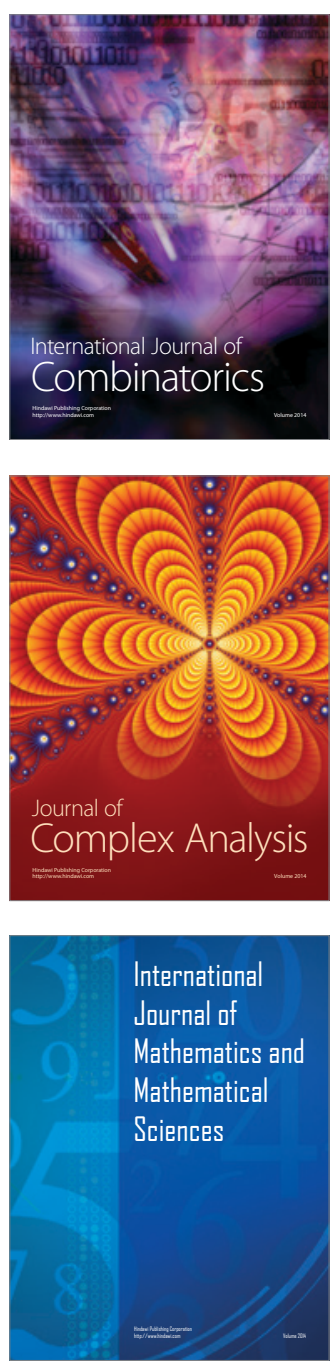
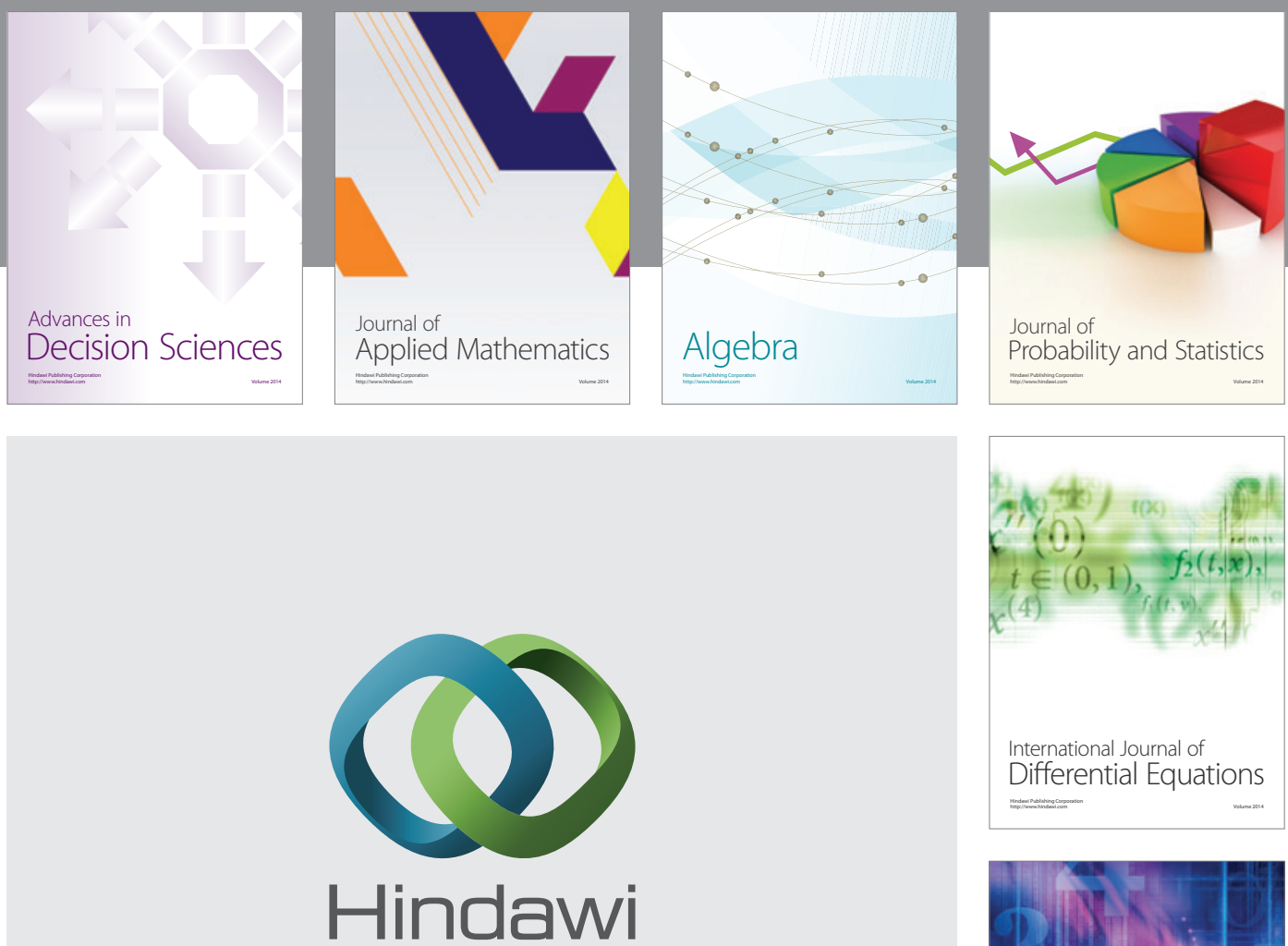

Submit your manuscripts at http://www.hindawi.com
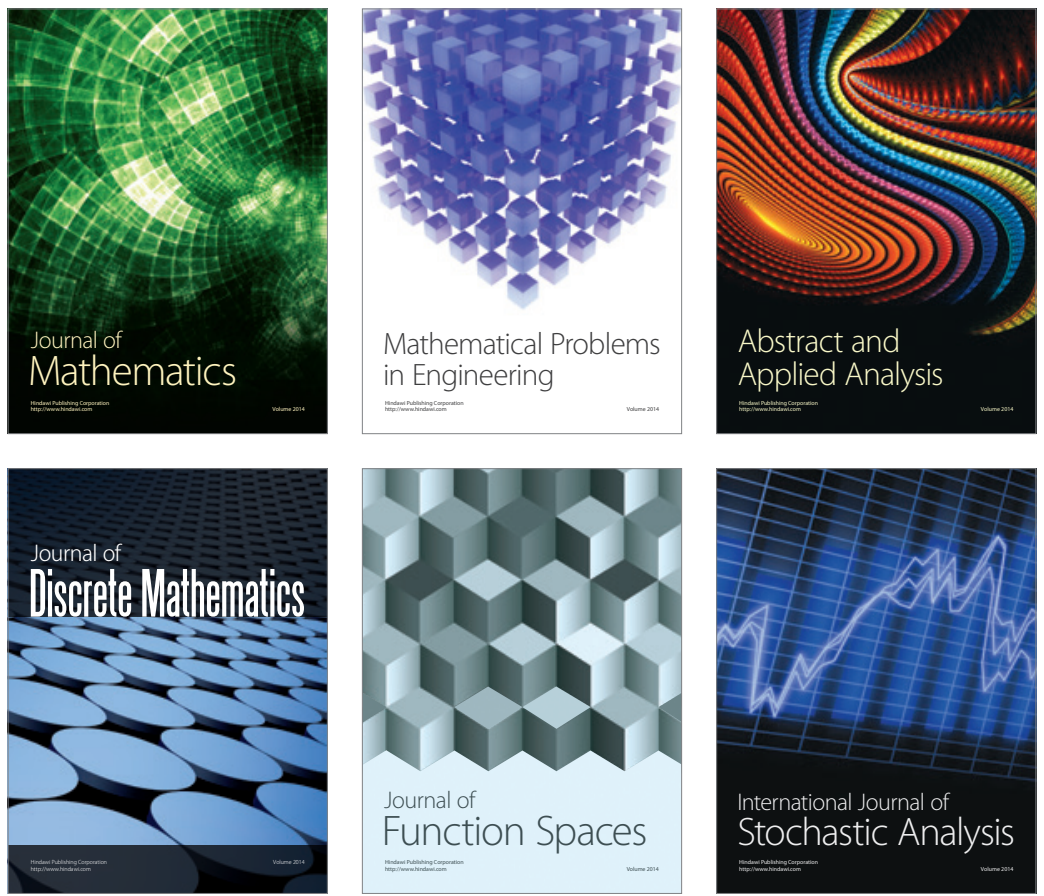

Journal of

Function Spaces

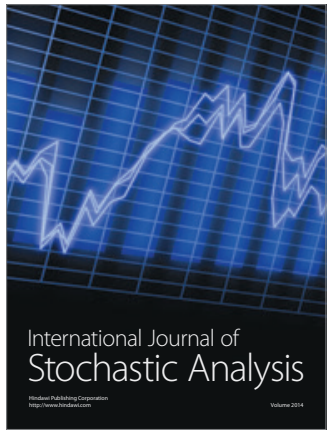

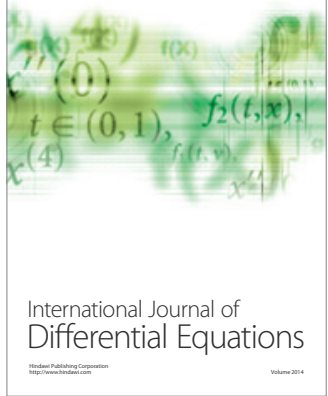
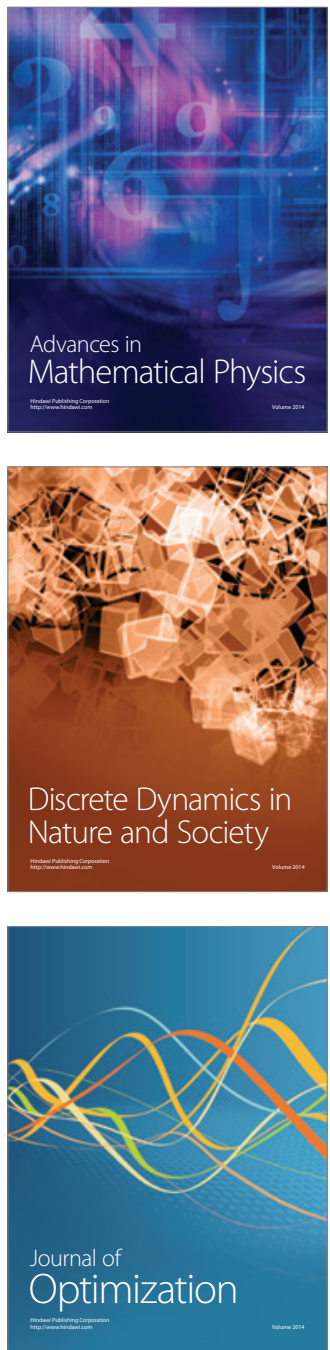